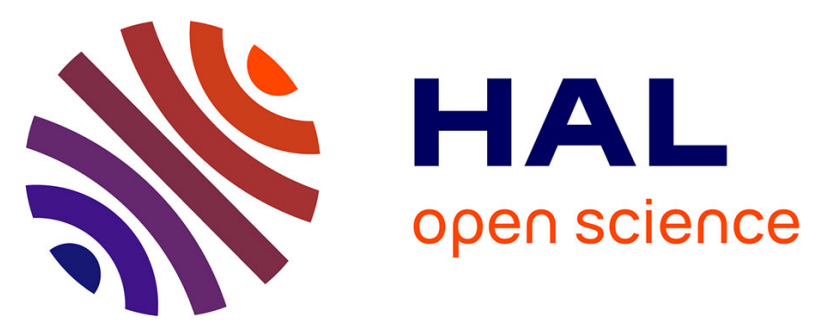

\title{
Variable temperature characterization of N,N'-Bis(n-pentyl)terrylene-3,4:11,12-tetracarboxylic diimide thin film transistor
}

Matthieu Petit, Ryoma Hayakawa, Toyohiro Chikyow, Jonathan P. Hill, Katsuhiko Ariga, Yutaka Wakayama

\section{To cite this version:}

Matthieu Petit, Ryoma Hayakawa, Toyohiro Chikyow, Jonathan P. Hill, Katsuhiko Ariga, et al.. Variable temperature characterization of N,N'-Bis(n-pentyl)terrylene-3,4:11,12-tetracarboxylic diimide thin film transistor. Organic Electronics, 2009, 10 (6), pp.1187-1190. 10.1016/j.orgel.2009.05.026 . hal-01122617

\section{HAL Id: hal-01122617 \\ https://hal.science/hal-01122617}

Submitted on 4 Mar 2015

HAL is a multi-disciplinary open access archive for the deposit and dissemination of scientific research documents, whether they are published or not. The documents may come from teaching and research institutions in France or abroad, or from public or private research centers.
L'archive ouverte pluridisciplinaire $\mathbf{H A L}$, est destinée au dépôt et à la diffusion de documents scientifiques de niveau recherche, publiés ou non, émanant des établissements d'enseignement et de recherche français ou étrangers, des laboratoires publics ou privés. 


\section{Variable temperature characterization of $N, N^{\prime}-B i s(n$-pentyl)terrylene-3,4:11,12- tetracarboxylic diimide thin film transisitor}

Matthieu Petit ${ }^{1 *}$, Ryoma Hayakawa ${ }^{1}$, Toyohiro Chikyow ${ }^{1}$, Jonathan P. Hill ${ }^{2}$, Katsuhiko Ariga ${ }^{2}$ and Yutaka Wakayama $^{1}$

${ }^{1}$ Advanced Electronic Materials Center, NIMS, 1-1 Namiki, Tsukuba, 305-0044 Japan

${ }^{2}$ World Premier International (WPI) Research Center for Materials Nanoarchitectonics (MANA), NIMS, 1-1 Namiki, Tsukuba, 305-0044 Japan

"present address: CINaM UPR3118 CNRS, Campus de luminy, Case 91313288 Marseille Cedex 09 France

corresponding authors: Matthieu Petit (matthieu.petit@univmed.fr), Yutaka Wakayama (wakayama.yutaka@nims.go.jp)

Organic thin film transistors (OTFT) based on $N, N^{\prime}$-Bis(n-pentyl)terrylene-3,4:11,12-tetracarboxylic diimide (TTCDI-5C) with $\mathrm{Al}$ or $\mathrm{Au}$ top contact electrodes were deposited on $\mathrm{SiO}_{2}(200 \mathrm{~nm}) / \mathrm{p}-\mathrm{Si}(001)$ substrates. Carrier mobility was examined as a function of temperature in the range from $50 \mathrm{~K}$ to $310 \mathrm{~K}$. Two distinct carrier transfer behaviours were observed: temperature independent behaviour below 150 $\mathrm{K}$ and thermally activated behaviour above $150 \mathrm{~K}$. Activation energies presented values of $85-130$ meV depending on the metal electrodes ( $\mathrm{Au}, \mathrm{Al}$ ), which can be attributed to the carrier traps at the interface and the energy-level offset between the lowest unoccupied molecular orbital (LUMO) and the work functions of the respective metals. 


\section{INTRODUCTION:}

OTFTs have received much attention since the mid nineties. Applications in devices such as active matrix displays have been already reported ${ }^{1,2}$. Although the performances of these devices are still poor relative to those composed of inorganic semiconductors, their fabrication processes are less complex than for their silicon counterparts, leading to a significant advantage in terms of fabrication costs. OTFTs based on p-type materials such as pentacene and oligothiophenes exhibit quite high carrier mobilities up to $0.1-8 \mathrm{~cm}^{2} \mathrm{~V}^{-1} \mathrm{~s}^{-1}{ }^{3-5}$ However for assembly of complementary circuits, high performance n-type materials are also required. Additionally thin films for use in OTFTs are generally in a polycristalline state and so charge carrier transport is strongly influenced by grains boundaries ${ }^{6}$. Thus it is necessary to identify suitable bulk n-type semi-conducting molecules, which form highly crystalline thin films with enhanced intermolecular orbital overlap. Of the known n-type semiconductor molecules, $\mathrm{N}$-alkyl perylene tetracarboxylic diimides (PTCDI-R) fulfill these expressed requirements. They have been widely studied and can exhibit carrier mobility as high as $1.3 \mathrm{~cm}^{2} \mathrm{~V}^{-1} \mathrm{~s}^{-1}$ in a vacuum. ${ }^{7.8}$ High electron affinities of $\mathrm{N}$ and $\mathrm{O}$ atoms modify molecular orbitals leading electrons to major carrier while the alkyl chain substituents contribute to improve molecular packing. For further improvement, fine tuning of molecular orbitals (HOMO, LUMO levels) as well as the energy-level offset (energy matching between molecular orbital and work function of electrodes) is essential.

Previously, we have demonstrated the potential of a family of molecules based on terrylene for use in field effect transistors. The expanded aromatic core of terrylene results in a small HOMO-LUMO gap and large electron affinity ${ }^{9}$. In the present study, we investigate the behaviour of the charge carrier mobility of OTFTs constructed using $N, N^{\prime}$-Bis(n-pentyl)terrylene-3,4:11,12-tetracarboxylic diimide (TTCDI-5C, cf. Fig.1a) with different metal electrodes to assess carrier transport in these OTFTs.

\section{EXPERIMENTS:}

TTCDI-5 thin films were deposited on $\mathrm{SiO}_{2} / \mathrm{Si}$ substrate in vacuum with a base pressure below $5 \times 10^{-9}$ Torr. A deposition rate of about $0.06 \mathrm{ML} \mathrm{min}^{-1}$ was used for all films prepared in this work. The thin films thickness is $15 \mathrm{ML}$. A detailed description of experimental procedure was given in previous work $^{9}$. Figure $1 \mathrm{~b}$ presents an AFM image of a TTCDI film deposited at an optimized substrate temperature of $140^{\circ} \mathrm{C}$. Film morphology consists of compact rectangular grains with an average area of $0.06 \mu \mathrm{m}^{2} /$ grain. Roughness of the surface is $2 \mathrm{~nm}$. From XRD spectra (not shown here), we found the molecules were highly ordered and oriented with the (001) axis normal to the surface substrate. 
For the thin film transistors (OTFT), all experiments including molecular deposition, electrode contact as well as electrical measurement were carried out in vacuum. First, the TTDCI films were deposited on thermally grown $\mathrm{SiO}_{2}(200 \mathrm{~nm}) / \mathrm{p}-\mathrm{Si}(001)$ substrates. Metals of electrodes with a thickness of $50 \mathrm{~nm}$ were deposited using an e-beam evaporator for aluminium and a heated crucible for gold. The channel length was $50 \mu \mathrm{m}$ and the width $400 \mu \mathrm{m}$. An illustration and photograph of the top-contact OTFT structure are shown in figure 2 (top). OTFTs thus prepared were transferred into the electrical measurement chamber for transistor analysis by means of a vacuum transfer system to avoid exposure to air. Electrical measurements were performed in vacuum of $10^{-5}$ Torr at a variable temperature from $50 \mathrm{~K}$ to $310 \mathrm{~K}$.

\section{RESULTS AND DISCUSSION:}

\section{A Thermal behaviour of carriers mobilities:}

Figure 2 (bottom) presents typical $I_{D}-V_{D}$ curves of the TTCDI-5C transistors at room temperature (gold electrode). A clear difference in the threshold voltages $\left(V_{t}\right)$ was observed depending on electrode metals. The $\mathrm{V}_{t}$ for $\mathrm{Au}$ and $\mathrm{Al}$ electrodes were $20 \mathrm{~V}$ and $16 \mathrm{~V}$, respectively. The main reason for the lower $\mathrm{V}_{\mathrm{t}}$ in the $\mathrm{Al}$ electrode device originate from its lower work function (4.3 eV for $\mathrm{Al}$ and $5.1 \mathrm{eV}$ for $\mathrm{Au}$ ).

We calculated the mobilities of the TTCDI-5C OTFTs in the temperature range from $50 \mathrm{~K}$ to $310 \mathrm{~K}$ in both devices prepared using gold or aluminium electrodes using the following equation ${ }^{10,11}$ :

$$
I_{D, s a t}=\frac{W}{2 \mathrm{~L}} C_{o x} \mu_{s a t}\left(V_{G}-V_{T}\right)^{2}
$$

where $C_{0 x}, \mu_{\text {sat }}$ and $V_{T}$ are the gate dielectric capacitance per unit area, field effect mobility at saturation regime and the threshold voltage, respectively. Then we prepared the Arrhenius plots of the carrier mobilities of the OTFTs which are shown in figure 3. These plots can be divided into two ranges: less temperature dependent range from $50 \mathrm{~K}$ to $150 \mathrm{~K}$ and thermal activation temperature range from 150 $\mathrm{K}$ to $310 \mathrm{~K}$. Below $150 \mathrm{~K}$, it can be regarded that the carriers are trapped at the defects and temperature is not high enough to activate these trapped carriers to conduction. This is a property of the TTCDI film and is not related to the metal used to prepare the electrodes.

A clear difference depending on the electrode material was observed in the temperature range above $170 \mathrm{~K}$. To interpret this observation, we referred to the multiple trapping and release model (MTR). It supposes that charge transport in the semiconductor is ruled by charges trapping into localized states in the forbidden gap followed by thermal release. ${ }^{12,8}$ Thus we fitted the Arrhenius plots using next 
equation:

$$
\mu=\mu_{0} \exp \left(\frac{-E_{a}}{k_{B} T}\right)
$$

where $\mu, \mathrm{k}_{\mathrm{B}}$ and $\mathrm{E}_{\mathrm{a}}$ are carrier mobility, the Boltzmann constant and the activation energy, respectively. The activation energies were determined to be $130 \mathrm{meV}$ and $85 \mathrm{meV}$ for $\mathrm{Au}$ and $\mathrm{Al}$ contacts respectively.

\section{B. Discussion:}

Two distinct factors -trapping at the interface and energy mismatch between work function and LUMO- are probably contributing to the difference in the activation energy. In the following sections, we discuss respective factors.

\section{Trapped carriers:}

To explain the difference between the values of the activation energies, we first evaluated carrier traps. In figure 4, both OTFTs exhibited positive threshold voltage shifts with decreasing temperature. Indeed at lower temperature there is less thermal energy available to activate trapped carriers into delocalized states. Thus more carriers remain trapped and screen the gate field. Therefore, OTFTS required a greater gate voltage to enable conduction ${ }^{7,13}$. The shifts in the threshold voltage $\Delta \mathrm{V}$ were 23 $\mathrm{V}$ for the Au contacts and $15 \mathrm{~V}$ for the Al contacts. The number of trapped carriers can be estimated using the following equation with the elementary charge $e^{7,13}$ :

$$
\mathrm{N}_{\mathrm{t}}=\frac{\Delta \mathrm{V} \mathrm{C}_{\mathrm{ox}}}{\mathrm{e}}
$$

In the case of gold electrodes, $\mathrm{N}_{\mathrm{t}}$ is about $2.4 \times 10^{12}$ carriers $/ \mathrm{cm}^{2}$ while the corresponding value for the aluminium electrodes is $1.9 \times 10^{12}$ carriers $/ \mathrm{cm}^{2}$. These values seem to be quite high when compared with the molecular density of TTCDI thin films which is typically in the range of $10^{14}$ molecules $/ \mathrm{cm}^{2}$. However $\mathrm{N}_{\mathrm{t}}$ is a total summation of carriers including those trapped at the insulator/organic and the metal/organic interfaces, as well as those fixed in the insulator and organic films. Among these trapped carriers, the observed difference in $\mathrm{N}_{t}$ for the respective electrode metals can be ascribed to the carriers trapped at the metal/organic interfaces. This means that the activation energies should be determined by taking into account the carrier transfer at the metal/TTCDI interface. Here we note that the threshold voltage of the OTFT with Al electrodes remained lower than that with gold electrodes. This gap is linked to the defects at the metal/organic layer interface in addition to the relative work 
function of the metals. Regarding the defects, it should be mentioned that Al was deposited using a cooled e-beam evaporator while gold was deposited using a heated crucible so that the substrate temperature for the case during gold deposition was slighty higher possibly generating defects and increasing the numbers of trapped carriers at the Au/TTCDI interface.

\section{HOMO/LUMO levels and metals work functions:}

With respect to the work functions of the electrode metals, we examined the energy level diagram involving HOMO/LUMO levels and work functions of the electrode metals as shown in figure 5. In passing from gold to aluminium, the difference in energy between work function and the LUMO level of TTCDI-5C molecules is reduced. Consequently injection of electrons into the LUMO, as well as into the defects states, becomes easier causing a decrease in the energy for activating the charges into the organic layer. This explains the difference between the activation energies $\left(E_{a}\right)$ of the different metal electrodes. Also, the mismatch between the Al work function and the LUMO is still around $0.78 \mathrm{eV}$ according to our diagram so that this barrier should affect the charges injection. This point has been raised previously and it has been proposed that the presence of an interfacial electric dipole layer lowers the barrier to electron injection and the apparent metal work function can vary by up to $1 \mathrm{eV}^{14-16}$.

\section{CONCLUSION:}

In summary we have designed OTFTs based on TTCDI-5C which operated as n-channel transistors. Two kinds of transistors were prepared containing gold or aluminium electrodes. Dependences of the carriers mobility and threshold voltage on temperature were investigated. Two different behaviours were observed for carrier transport: a temperature independent behaviour below $170 \mathrm{~K}$ and a thermally activated one at higher temperature. Activation energies were calculated from the temperature dependence of the carrier mobility. Those were $85 \mathrm{meV}$ for aluminium contacts and $130 \mathrm{meV}$ for gold contacts. The difference in activation energies can be explained by the energy matching mainly between work function of electrodes metals and the LUMO level of the TTCDI-5C molecules. Additionally, defects and dipoles produced at the metal/molecule interface also influence carrier transport. These experimental results emphasize the importance of optimizing the energy levels of molecules with work functions of the metal electrodes, as well as the interface formation techniques. 


\section{REFERENCES:}

1. C.D. Dimitrakopoulos, and P.R.L. Malenfant, Adv. Mater. 14, 99 (2002).

2. G. Horowitz, J. Mater. Res. 19, 1946 (2004).

3. T. W. Kelley, P. F. Baude, C. Gerlanch, D. E. Ender, D. Muyres, M. A. Haase, D. E. Voge, and S. D. Theiss, Chem. Mater. 16, 4413 (2004).

4. V. Podzorov, S. E. Sysoev, E. Loginova, V. M. Pudalov, and M. E. Gershenson, Appl. Phys. Lett. 83, 3504 (2003).

5. H. Sirringhaus, R. H. Friend, X. C. Li, S. C. Moratti, A. B. Holmes, and N. Feeder, Appl. Phys. Lett. 71, 3871 (1997).

6. D. Knipp, R. A. Street, B. Krusor, R. Apte, and J. Ho, J. Non-Cryst. Solids 299, 1042 (2002).

7. R. J. Chesterfield, J. C. McKeen, C. R. Newman, P. C. Ewbank, D. A. da Silva Filho, J.-L. Bredas, L. L. Miller, K. R. Mann, and C. D. Frisbie, J. Phys. Chem. B. 108, 19281 (2004).

8. R. J. Chesterfield, J. C. McKeen, C. R. Newman, C. D. Frisbie, P. C. Ewbank, K. R. Mann, and L. L. Miller, J. Appl. Phys. 95, 6396 (2004)

9. M. Petit, R. Hayakawa, Y. Shirai, Y. Wakayama, J. P. Hill, K. Ariga, and T. Chikyow, Appl. Phys. Lett. 92, 163301 (2008).

10. C. R. Newman, C.D. Frisbie, D.A da Silva Filho, J-L. Bredas, P.C. Ewbank, and K.R. Mann, Chem. Mater. 16, 4436 (2004).

11. G. Horowitz, Adv. Mater. 10, 365 (1998).

12. G. Horowitz, M.E. Hajlaoui, R. Hajlaoui, J. Appl. Phys. 87, 4458 (2000).

13. G. Horowitz, and P. Delannoy, J. Appl. Phys. 70, 469 (1991).

14. I. H. Campbell, J. D. Kress, R. L. Martin, D. L. Smith, N. N. Barashkov, and J. P. Ferraris, Appl. Phys. Lett. 71, 3528 (1997).

15. I. G. Hill, A. Rajagopal, A. Kahn, and Y. Hu, Appl. Phys. Lett. 73, 662 (1998).

16. L-L. Chua, J. Zaumseil, J-F. Chang, E. C-W. Ou, P. K-H. Ho, H. Sirringhaus, and R. H. Friend, Nature 434, 194 (2005). 


\section{Figures captions:}

Figure 1: (a) Chemical structure of the TTCDI-5C molecule. (b) AFM image of the TTCDI-5C thin film.

Figure 2: (top) Scheme and optical microscope image of the top contact TTCDI-5C OTFT, (bottom) typical drain current-drain voltage curves of TTCDI-5C OFET.

Figure 3: Arrhenius plot of the carrier mobilities of the TTCDI-5C OFETS with gold and aluminium contacts.

Figure 4: Evolution of the threshold voltage versus the temperature.

Figure 5: Energy diagram of HOMO/LUMO levels of TTCDI-5C molecules and work function of god and aluminium. 

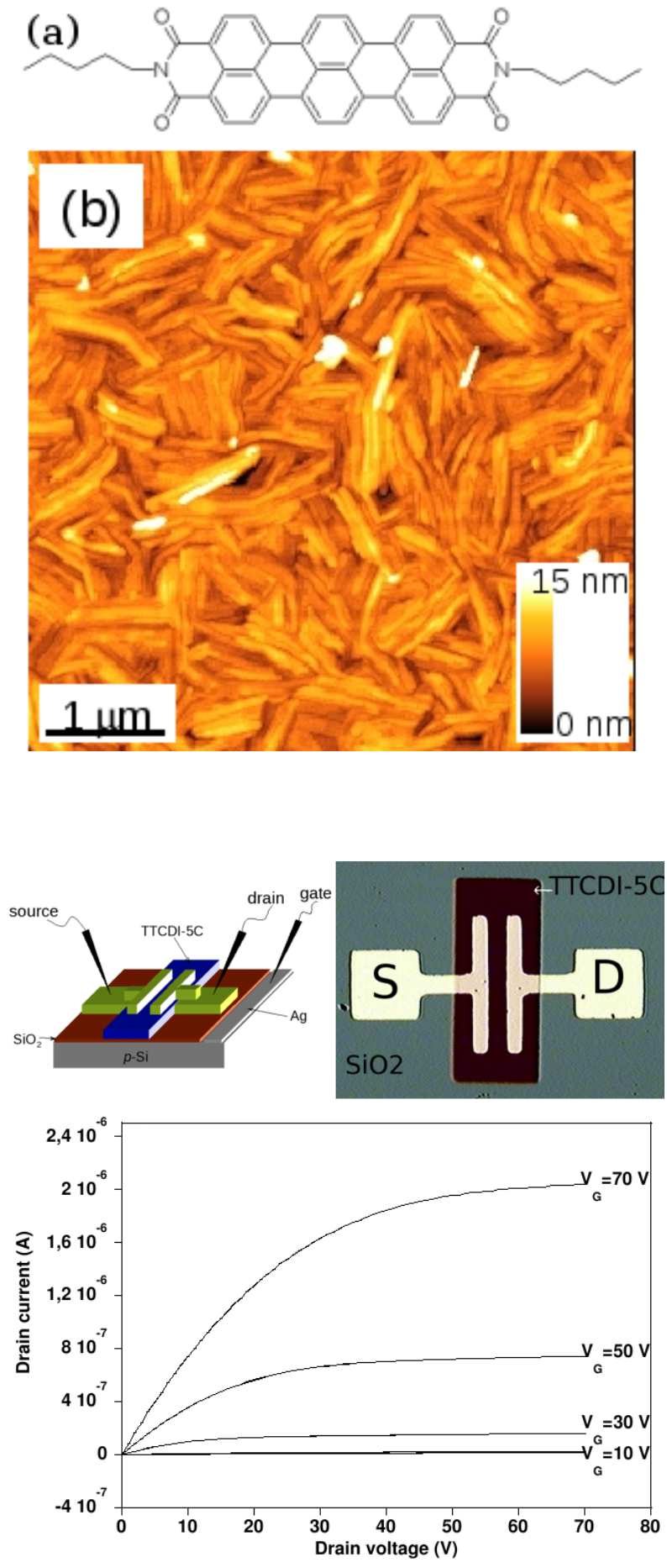

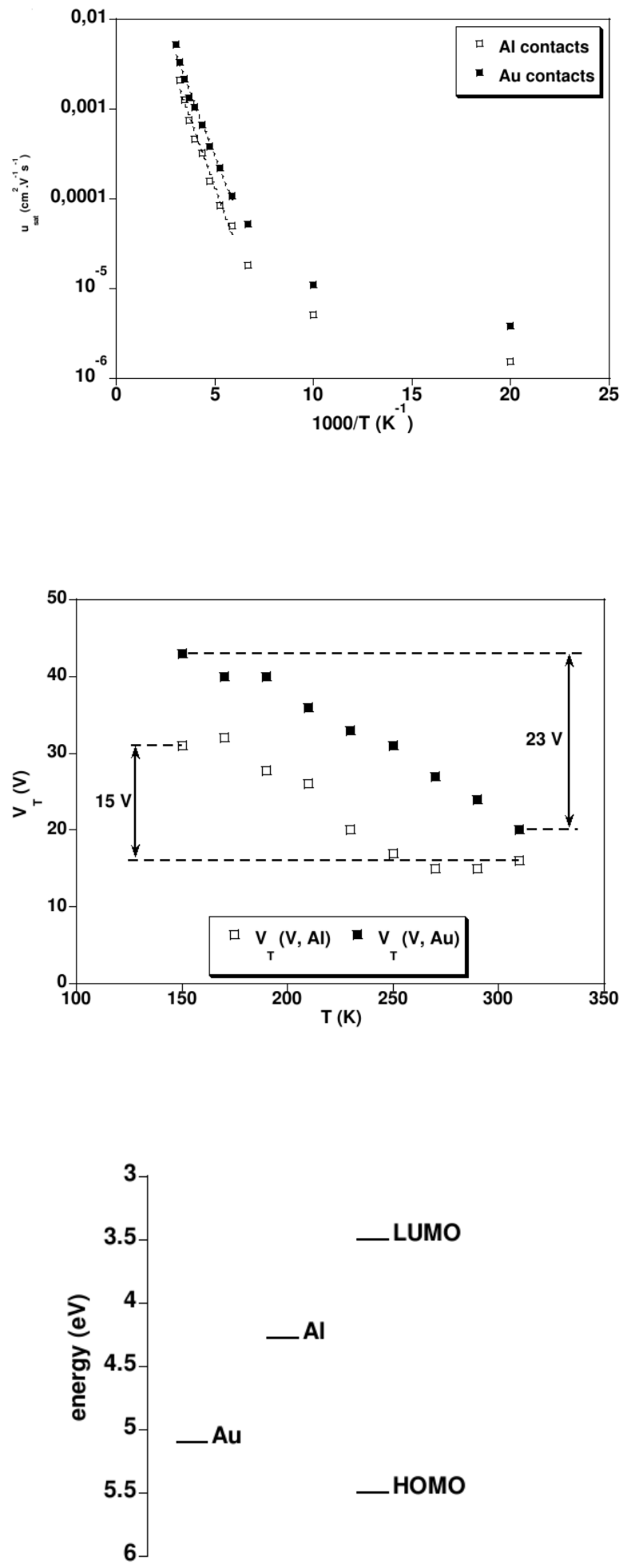
